\title{
Vision Rehabilitation by Electrical Retinal Stimulation: Review of Microelectrode Approaches
}

\author{
Jong-Mo Seo ${ }^{1,2}$, Kyung Hwan Kim³, Yong-Sook Goo ${ }^{4}$, Kwang-Suk Park ${ }^{5}$, \\ Sung June Kim", Dong-Il "Dan" Cho ${ }^{1}$ and Hum Chung,", \\ ${ }^{1}$ Department of Electrical Engineering, School of Engineering, Seoul National University \\ ${ }^{2}$ Department of Ophthalmology, School of Medicine, Seoul National University \\ ${ }^{3}$ Department of Biomedical Engineering, Yonsei University \\ ${ }^{4}$ Department of Physiology, School of Medicine, Chungbuk National University \\ ${ }^{5}$ Department of Biomedical Engineering, School of Medicine, Seoul National University
}

(Received December 9, 2012; accepted February 13, 2012)

Key words: retinal prosthesis, electrical neural stimulation, microelectrode arrays

Vision rehabilitation in the blind seems to be the ultimate goal of ophthalmologic treatments. Among the several different approaches, electrical retinal stimulation showed the most promising results for restoring vision. Microelectrode arrays based on a flexible polymer developed and used for pattern electrical retinal stimulation, and epiretinal, subretinal and suprachoroidal approaches are adopted for the surgical implantation of electrodes. Stimulation patterns can be provided from an external stimulator through wireless signal transfer or can be given by implanted photodiode arrays with an external power supply. In vitro and in vivo studies revealed that the retinal implant can be used for clinical purposes, and clinical trials showed that blind volunteers who were subjected to retinal implant surgery could recognize various shapes and their surroundings.

\section{Introduction}

The early step of vision starts from light perception. Visible light reaches the retina through the clear cornea and the crystalline lens, and the photoreceptors of the retina convert light to neural signals that will be delivered to the visual cortex of the brain through the optic nerve, lateral geniculate nucleus and optic radiation. Irrecoverable corneal damage can often be overcome by corneal transplantation, ${ }^{(1)}$ and cataract of the crystalline lens can be treated by cataract removal and with an artificial intraocular lens. ${ }^{(2)}$ However, there is no successful treatment for photoreceptor damage in the retina. ${ }^{(3)}$ Even

${ }^{*}$ Corresponding author: e-mail: chungh@snu.ac.kr 
though there are neural cells remaining in the retina after photoreceptor degeneration or damage, they cannot convert light to neural signals.

Gene therapy can be an option for hereditary photoreceptor degeneration. ${ }^{(4)}$ However, there are more than one hundred mutation loci already known, which not only increases the expense of gene study but also makes the target gene selection difficult. Medication such as ciliary neurotrophic factors (CNTFs) can be a good choice, ${ }^{(5)}$ but the clinical trial of CNTFs was not satisfactory. Moreover, both modalities are unable to restore already degenerated photoreceptors. Photoreceptor or stem cell transplantation has been attempted. In humans, transplanted fetal photoreceptors do not integrate into the remaining retinal neurons.(6) In animals, homogeneous transplantation of stem cells results in malignant proliferation, ${ }^{(7)}$ and in the case of retinal transplantation, the transplanted retina does not establish any synaptic connection with the host neurons. ${ }^{(8)}$ Some papers showed successful synapse formation between differentiated stem cells and host cells, ${ }^{(9)}$ and pupil response to light in mouse. ${ }^{(10)}$ However, these results cannot be directly applied to humans because the differentiation stage of these stem cells is equivalent to the second trimester of gestational age in humans, and photoreceptor stem cells of this stage cannot be acquired or established until now. Optogenetic approaches, in which the channelopsin ${ }^{(1)}$ or halorhodopsin ${ }^{(12)}$ genes are transferred to the remaining retinal neural cells and are expressed on the cell membrane, are newly introduced and showed some positive results. These proteins can respond to light and generate action potentials to be used as neural signals, but transferring the genes and maintaining stable gene expression in the human retina are difficult to achieve. Chemical stimulation of the remaining retinal neurons using a neurotransmitter has also been studied, ${ }^{(13)}$ but the glutamate excitotoxicity and the almost impossible, controlled release of the neurotransmitter in vivo delay the advancement of this project.

\section{Electrical Neural Stimulation in Visual Pathway}

Stimulation of remaining neural cells to evoke action potential has long been studied in degenerative retinal diseases. ${ }^{(14-18)}$ Even though the action potentials are generated by ionic flow across the cell membrane and propagate along the axonal membrane through voltage-sensitive ion channels, scientists know that electrical stimulation of the nerve can induce an action potential or can mimic the propagation of an action potential ${ }^{(19,20)}$ Thus, it is natural that patients reported the 'phosphene' resembling fluorescent light in their sight upon electrical visual cortex stimulation during surgery. ${ }^{(21)}$ Brindley and Lewin's experiment on the blind showed that the visual cortex could be a site for electrical stimulation to restore vision, ${ }^{(22)}$ and Dobelle's experiment created hope ${ }^{(23)}$ (Fig. 1). However, direct electrical stimulation of the visual cortex bears several potential dangers, because the stimulation site can be an epileptogenic focus by an unwanted spreading of neural activity, ${ }^{(24)}$ and the infection or chemical inflammation of the cortex or meninges is potentially severely harmful. ${ }^{(25)}$ Also, the topological mapping between the retina and visual cortex is a big hurdle. This retinotopic mapping seems also difficult in optic nerve stimulation and lateral geniculate nucleus stimulation. Veraart et al. ${ }^{(26)}$ implanted silicone-based platinum cuff electrodes on the optic nerve of the blind, and the patient 


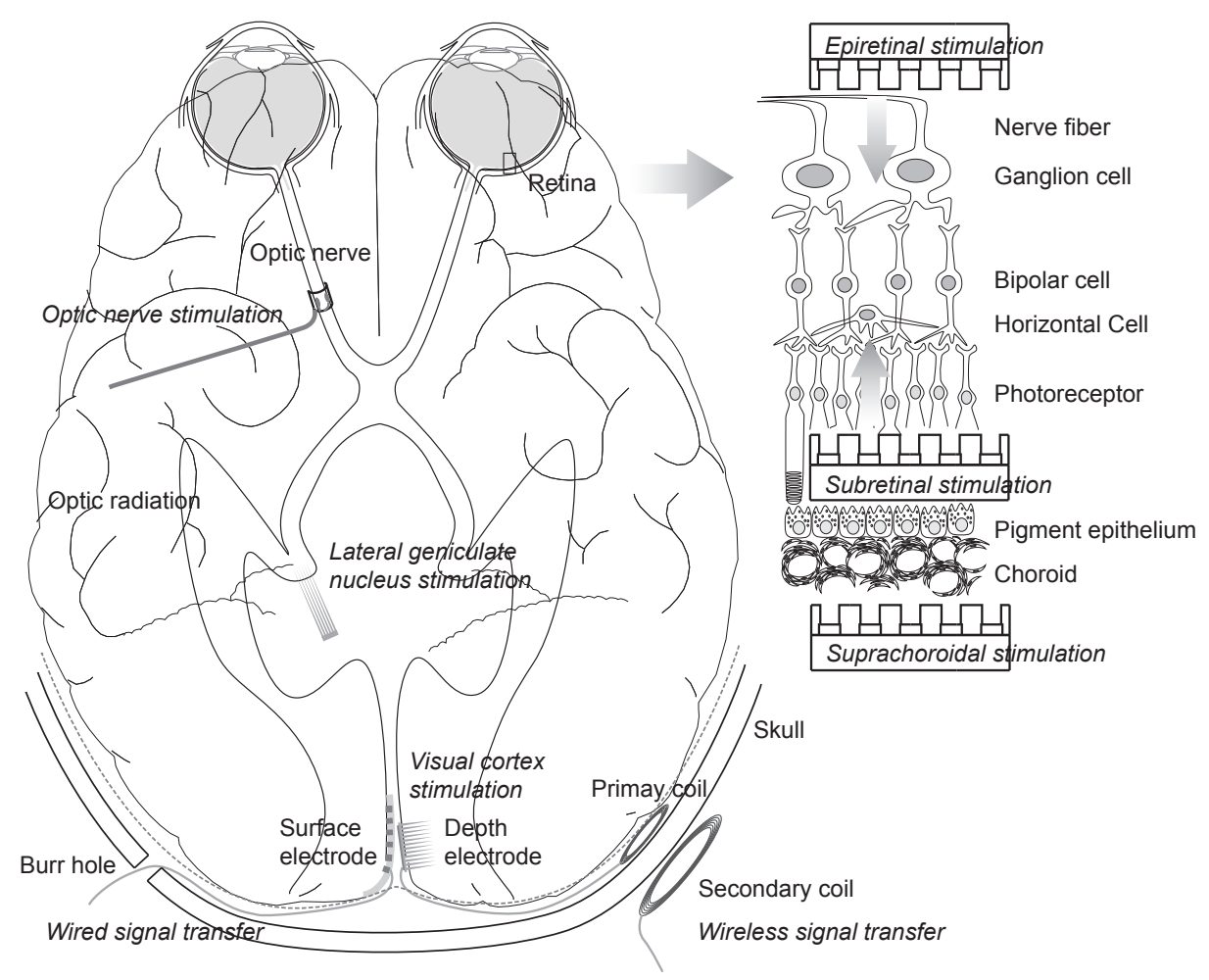

Fig. 1. Visual pathway and candidate of stimulation sites to create visual perceptions.

could recognize objects upon four channel electrical stimulation (Fig. 2). However, the patient needed spatial mapping using an external program, and the low resolution of the electrodes required a long time for recognition. ${ }^{(27)}$ Pezaris and Reid ${ }^{(28)}$ tried to stimulate the lateral geniculate nucleus, but this nucleus is a very deep-seated structure within the brain, and the sinuses of the cerebral vein and cerebral artery are dangerous during surgery.

\section{Pattern Electrical Retinal Stimulation}

Pattern electrical retinal stimulation can also evoke visual perception. ${ }^{(29)}$ In the beginning, the stimulation site was considered very important, because the model for the electrical retinal stimulation was composed of defective photoreceptor layers and the preserved remaining neuronal layers such as bipolar cells and ganglion cells. ${ }^{(30)}$ Thus, the subretinal stimulation might activate the bipolar cells, utilizing the intraretinal neural networks such as the receptive field, but might block the intercellular metabolic transport 


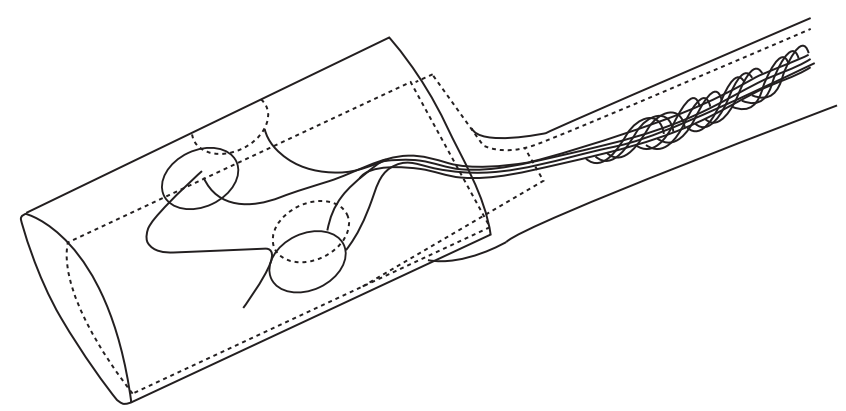

Fig. 2. Cuff electrode for optic nerve stimulation.

between the underlying retinal pigment epithelial cells and the overlying bipolar cells. ${ }^{(31)}$ Epiretinal stimulation was considered to have higher stimulation thresholds because this method cannot establish close contacts between the electrodes and the ganglion cells, and also, ganglion cells might have higher thresholds for stimulation than bipolar cells. $^{(32)}$ Epiretinal attachment or fixation of the electrodes could be a great challenge, but they would not block the metabolic transport. The possibility of retinal nerve fiber stimulation exists, and this will result in the activation of a broader area than that in the case of focal retinal stimulation. (33) Suprachoroidal stimulation might require a much higher stimulation threshold and poorer resolution because the distance between the electrodes and retinal neurons is significantly farther than in other approaches. ${ }^{(34)}$

Interestingly, many of these assumptions turn out to be insignificant in their impact. Histological examination of the photoreceptor-degenerated retina showed that the remaining neural cells undergo disorientation and reconfiguration, and as a result, bipolar cells and ganglion cells no longer preserve their receptive field structure. ${ }^{(35)}$ This means that the target cells of the subretinal stimulation and epiretinal stimulation would be almost the same, namely, mixed ganglion and bipolar cells. Also, the degenerated retina is significantly thinner than the normal retina; ${ }^{(36)}$ thus, they could be nourished by the retinal vessels only, and the retinal pigment epithelium is also greatly decreased in number in the photoreceptor-degenerated eye. Therefore, they do not contribute much to the support of the remaining retinal neurons. These indicate that the subretinal implantation should not be blamed for the cutting of the metabolic transport. ${ }^{(37)}$ The choroidal vessels are also thinner in degenerated eyes than in healthy eyes; thus, the threshold for the suprachoroidal approach is not much higher than predicted. ${ }^{(38)}$ Even though the threshold of stimulation is higher in the epiretinal approach than in the subretinal approach, they can be met by current technology.

\section{Electrode Materials for Retinal Prosthesis}

Silicone-based platinum and polyimide-based gold electrodes ${ }^{(39-44)}$ are the most frequently used materials in retinal prostheses. For ophthalmologic use, polyimide was 
adopted as the haptic material of intraocular lens, ${ }^{(45)}$ and silicone has been used as the tube for anterior chamber drainage of a glaucoma implant and the conduit in nasolacrimal duct reconstruction surgery. ${ }^{(46)}$ Both of them are well known because of their stability and biocompatibility in the eye and its adnexa. However, if they are used as a base material for the electrodes, the semiconductor fabrication processes may alter their characteristics. Thus, biocompatibility tests for microelectrode arrays should be carried out. Both silicone-based platinum and polyimide-based gold electrodes have good in vitro biocompatibility. ${ }^{(47)}$ Parylene-based electrodes also showed good biocompatibility, but their high flexibility makes handling difficult. The liquid crystal polymer (LCP), which is partially crystalline aromatic polyester, has been adopted recently and has also shown good biocompatibility in vitro as base material. Concerning the electrode material itself, platinum, gold, iridium oxide, and titanium nitride were evaluated. In early reports, titanium nitride was suspected to be harmful, ${ }^{(48)}$ but further investigation proved that all the mentioned materials can be used safely as electrodes for retinal stimulation.

In vivo biocompatibility and stability require further evaluation. In vivo circumstances are harsher than the in vitro state, because continuous frictional force or pressure will be provided, and the salty body fluid will continuously attack the metallic surface and binding sites. The International Standard Organization (ISO) defined several protocols for in vivo evaluation, such as tests for local effect after implantation, tests for irritation and delayed-type hypersensitivity, tests for systemic toxicity, and identification and quantification of degraded products from polymeric medical devices. ${ }^{(49)}$ In this two-year follow-up of the polyimide-gold electrode array over the retina, there was no degradation or dissolution of the polyimide or gold materials. However, dehiscence was observed between the gold and polyimide layers, which might induce current leakage from the gold electrodes to adjacent electrodes or surrounding tissues. ${ }^{(50)}$ Calcification of the silicone intraocular lenses was reported, ${ }^{(51)}$ and this will make the lens opaque and hard or brittle. This is also true for the base polymer for the microelectrode arrays; thus, more study is required for the use of silicone in retinal prosthesis. In the case of LCP, it has not been well studied in terms of long-term in vivo biocompatibility and stability, but preliminary results are promising. ${ }^{(47)}$

\section{Surgical Techniques for Retinal Implantation}

As previously discussed, there have been debates on the best stimulation site using microelectrode arrays. However, as previously discussed, the efficiency and stability of the implanted electrodes depending to their location are less important than the risk of surgical complication according to the operation techniques, particularly in the retinal prosthesis.

The subretinal electrode implant technique has been established by creating an iatrogenic retinal detachment and reattachment of the retina by fluid-air exchange, and silicone oil injection into the vitreous cavity. ${ }^{(52)}$ This 'ab interno' technique is a creative modification of macular translocation, ${ }^{(53)}$ and subretinally implanted electrodes can also be explanted for the replacement with a newer version of the electrodes without causing any further surgical damage to the remaining retinal tissue. However, if the patient has 
a severely degenerated retina, the remaining retinal neural cell layer is much thinner and weaker than a healthy one, and also, the pigment epithelial cells and Muller cells sometimes mingle with the remaining retinal neurons, resulting in a brittle retina even with gentle manipulation.

A novel 'ab externo' approach for subretinal or suprachoroidal implantation of electrodes has been introduced by modifying scleral tunnel technique used in cataract surgery. ${ }^{(54)}$ After conjunctival incision, a scleral tunnel is created toward the posterior pole from the limbal sclera until the tunnel reaches the choroid. After meticulous hemostasis, the choroid can be cut to reach the subretinal space, and the electrode array can be introduced into the subretinal space. Without performing a choroidal incision, the electrode array can be introduced into the suprachoroidal space, and all these procedures will be enhanced by the use of viscoelastics such as hyaluronate. However, cutting the choroidal vessels is always dangerous and there might also be a high risk of retinal prolapse or tear on the choroidal incision site.

This problem has been solved by combining 'ab interno' and 'ab externo' techniques. ${ }^{(55)}$ A very small, localized retinal detachment at the choroidal incision site is established by subretinal viscoelastics injection before choroidal incision, which will reduce the risk of retinal prolapses or tears. Moreover, this small retinal detachment can be reattached more readily than the detachment throughout the electrode insertion passage. However, the guide-assisted electrode insertion under the subretinal space may cause damage to the remaining neural retinal tissue.

The scleral pocket technique has been proposed for suprachoroidal stimulation. ${ }^{(34)}$ The eyeball is rotated to expose the posterior pole of the eye where the macula locates, and a deep scleral tunnel or pocket is made to insert the electrode arrays under the macula. Thin fibrous layers of the sclera will remain over the choroid by this surgical technique, and this does not considerably increase the impedance of the electrodes but decrease the risk of suprachoroidal hemorrhage.

For the epiretinal fixation of electrode arrays on the retina, a novel titanium tack has been developed and used. ${ }^{(56)}$ Conventional titanium tacks were too large to be used for the epiretinal fixation of the electrodes and could not hold the electrodes to the retina as close as physiologically necessary. For this purpose, a small titanium retinal tack with a spring and collar on its neck has been proposed. This collar will push the electrode toward the retina without generating too much pressure on the underlying neural cells. However, this tack cannot be easily removed, which will make the replacement of the electrode array with a newer one difficult. By modifying the hole design on the electrode array as an open-circular form, sliding out the electrodes can be possible without removing the retinal tacks. ${ }^{(57)}$

The silicon retinal tack has been produced by semiconductor microfabrication technology, and the material was changed to poly-methyl methacrylate (PMMA) by Lithographie, Galvanoformung und Abformung (LiGA). ${ }^{(58)}$ Because PMMA is translucent, we can observe the underlying tissues and electrode holes. By adding scales in the shaft of the tack in the form of regularly spaced holes, the penetration depth of the retinal tack can be measured using optical coherent tomography (OCT). 


\section{Electrophysiology of Retinal Neural Cells upon Electrical Stimulation}

The receptive fields composed of photoreceptors, bipolar cells, horizontal cells and ganglion cells are the classical model for understanding the neural network of the retina. ${ }^{(59)}$ After photoreceptor damage, this network gradually loses its regular intercellular connections. This might be due to the loss of regular signal delivery from photoreceptors to other neural cells, and the remaining neural cells will start making abnormal or unpredictable interconnections. ${ }^{(60)}$ As a result, the electrical stimulation threshold might be unpredictable, and even the aberrant firing of the neural signals can be generated.

Neural signal analysis using a multichannel electrode array is a useful technique for the clarification of these mechanisms. The excitation of neural cells and thresholds of electrical stimulation were investigated in chicken retinas. ${ }^{(61)}$ Pattern stimulation was successfully mimicked, and the responses of the upper neurons upon the electrical stimulation were studied by using several neurotransmitter blockers. On the intraretinal neural network analysis in the degenerative retina, the slow wave component was found, which cannot be observed in healthy retinas. ${ }^{(62)}$ Even with the slow wave components, the remaining neural cells can be stimulated on demand, and the original stimulation signals can also be retrieved and predicted from the existence of the slow waves. ${ }^{(63)}$ The threshold for electrical stimulation is higher in the degenerative retina than in the normal retina. ${ }^{(64)}$

Patch clamp and single-channel recording techniques also contributed much to the understanding of the electrical neural stimulation mechanisms. In patch clamp studies, electrical stimulation of the neural cells was found to be due to the activation of voltagedependent ion channels on the axonal hillock and axon, not by the activation of the neural cell body itself. ${ }^{(20)}$ Also, the sinusoidal wave stimulation might be more effective than the conventional rectangular wave stimulation, ${ }^{(65)}$ and the on- and off-ganglion cells respond differently to the same electrical stimulation. ${ }^{(66)}$ In the single rod-shaped electrode experiment for acute stimulation in human volunteers, the size and area of phosphene perception by the volunteers did not sometimes match with the stimulation size and area. ${ }^{(67)}$ This can be explained as the retinal nerve fiber layer activation upon epiretinal stimulation, and is supported by in vitro experimental results.(20)

\section{Evaluation of Retinal Implants in Vivo}

Several groups have started clinical trials with different systems several years ago. These include in vivo biocompatibility and stability tests, and also functional aspects.

'One-chip' silicon retinal prostheses with 1,000 photodiode-electrode cells were fabricated by Optobionics ${ }^{\mathrm{TM}} \cdot{ }^{(68)}$ Even though the photodiode array chip tolerated the in vivo condition very well and showed almost no toxicity to the retina, this chip could not generate sufficient current or voltage to stimulate the remaining retinal neurons in the presence of day light. As a result, the device could not restore vision. Minute currents generated by this chip inside the eye might have a neurotrophic effect for the preservation of the remaining neurons. ${ }^{(69)}$ 
The company Second Sight ${ }^{\mathrm{TM}}$ has started a multicenter trial with their silicone-based platinum microelectrode arrays ${ }^{(70)}$ (Fig. 3). The electrode array is implanted epiretinally and all electrical stimulation signals are delivered into the eye through the wire from a signal generation chip, which is located on the temporal side of the eye in the orbit. An external camera mounted on eyeglasses grabs images in front of the patient, and the captured images are processed and delivered to the signal generation chip by wireless transmission. Patients were able to recognize various shapes and several grades of brightness with this device. Some patients also reported color perception. Close observation should be paid on how much this device can be beneficial to the patient's daily life.

Retina Implant AG has also extensively tested its device in volunteers. ${ }^{(71)}$ A polyimide-covered semiconductor chip contains photodiodes and stimulation electrodes, and the chip is connected to a wire that provides external electrical currents to the chip (Fig. 4). There is a gate controller in the chip that modifies the level of the externally supported current to the stimulation electrode according to the amount of light delivered to each photodiode. This overcomes the weakness of the Optobionics ${ }^{\mathrm{TM}}$ Artificial Silicon Retina $\left(\mathrm{ASR}^{\circledR}\right.$ ) implant, and some recipients can recognize various objects on a white dining table and they can even read large characters. ${ }^{(72)}$

These functional aspects are being evaluated from the subjective responses of the patients, so this method has low reproducibility and validity. Also, this cannot be used in animal tests. For objective and quantitative analyses, functional magnetic resonance imaging (MRI) can be considered for the evaluation. However, this cannot be applicable if the prosthesis contains ferro-magnetic components.

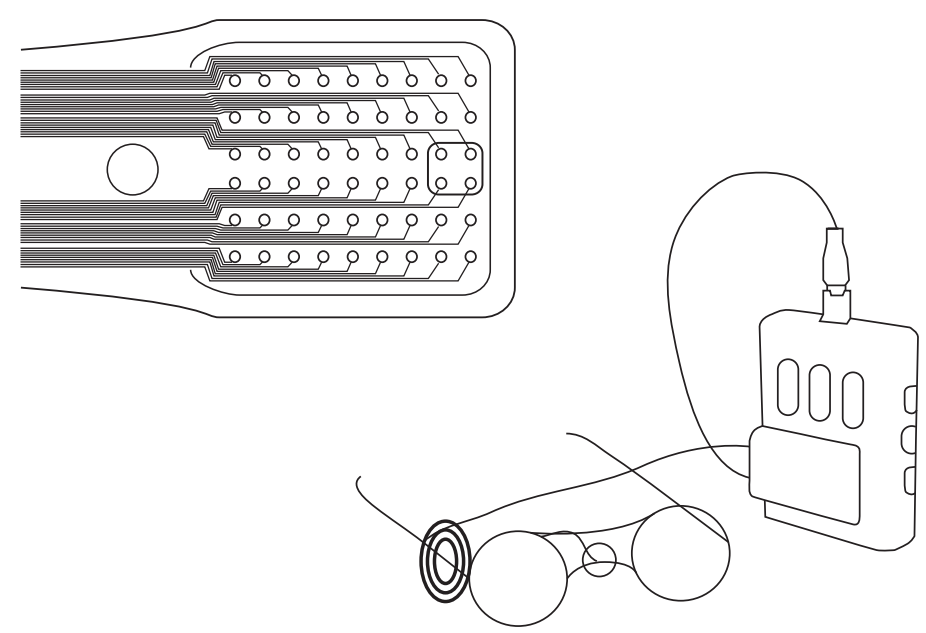

Fig. 3. Argus $^{\circledR}{ }^{\mathrm{T}}{ }^{\mathrm{TM}}$ microelectrode array and external wearable stimulation system developed by Second Sight ${ }^{\mathrm{TM}}$. 


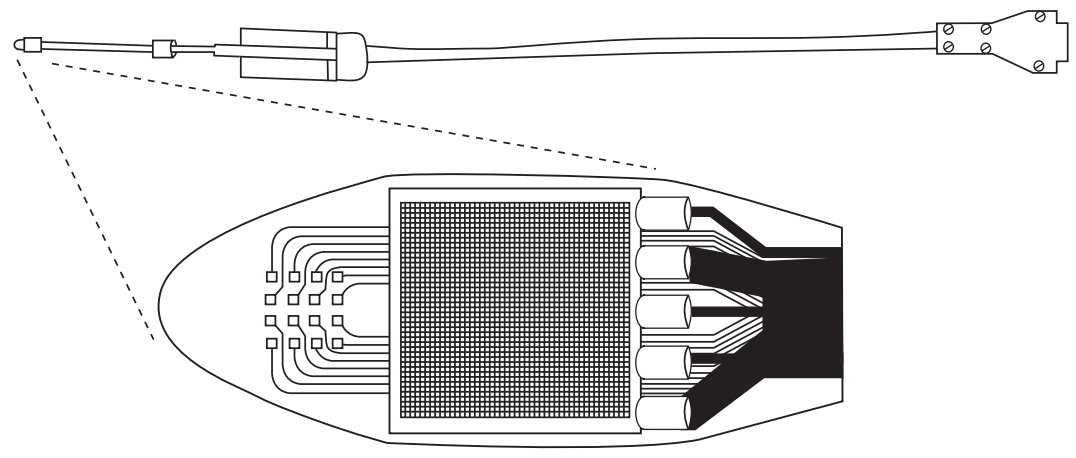

Fig. 4. Photodiode-microelectrode-coupled multichannel retinal stimulator developed by Retina Implant AG.

In animals, the evoked potential on the visual cortex can be measured invasively by using a screw electrode penetrating the skull over the visual cortex. ${ }^{(73)}$ This idea was extended with $4 \times 4$ needle electrodes implanted on the visual cortex, and the cortical responses were correlated with the pattern electrical retinal stimulation. ${ }^{(42)}$ For the noninvasive, objective evaluation, positron emission tomography (PET) is under investigation. ${ }^{(74)}$ Responses of the visual cortex upon the electrical retinal stimulation can be compared with that upon light stimulation, and by using this method, the most appropriate stimulation strategy can be investigated.

\section{Conclusions}

Retinal implants for the restoration of vision give hope for the blind. Various biopolymers and electrodes are under investigation, and the effective perception of light and the delivery of electrical stimulation to the remaining retinal neurons are still big challenges. Although some clinical trials have already started, there is much to be improved and investigated for the successful application of retinal prosthesis to patients.

\section{Acknowledgements}

This work was supported by the Korea Health 21 R\&D Project A050251 of MIHWAF, Technology Innovation Program 10033634 of MKE, Public Welfare \& Safety R\&D Project 2010-0020847 and Basic Research Program 2011-0027325 of MEST. 


\section{References}

1 M. K. Kim, W. R. Wee, C. G. Park and S. J. Kim: Curr. Opin. Organ Transplant. 16 (2011) 231.

2 M. Lundström and K. Pesudovs: J. Cataract Refract. Surg. 37 (2011) 945.

3 N. D. Bull and K. R. Martin: Stem Cells. 29 (2011) 1170.

4 M. M. Liu, J. Tuo and C. C. Chan: Br. J. Ophthalmol. 95 (2011) 604.

5 D. F. Emerich and C. G. Thanos: Curr. Opin. Mol. Ther. 10 (2008) 506.

6 M. S. Humayun, E. de Juan, M. del Cerro, G. Dagnelie, W. Radner, S. R. Sadda and C. del Cerro: Invest. Ophthalmol. Visual Sci. 41 (2000) 3100.

7 S. Arnhold, H. Klein, I. Semkova, K. Addicks and U. Schraermeyer: Invest. Ophthalmol. Visual Sci. 45 (2004) 4251.

8 F. Ghosh, K. Engelsberg, R. V. English and R. M. Petters: Graefe's Arch. Clin. Exp. Ophthalmol. 245 (2007) 835.

9 L. Zhou, W. Wang, Y. Liu, J. F. de Castro, T. Ezashi, B. P. Telugu, R. M. Roberts, H. J. Kaplan and D. C. Dean: Stem Cells. 29 (2011) 972.

10 R. E. MacLaren, R. A. Pearson, A. MacNeil, R. H. Douglas, T. E. Salt, M. Akimoto, A. Swaroop, J. C. Sowden and R. R. Ali: Nature 444 (2006) 203.

11 H. Tomita, E. Sugano, H. Yawo, T. Ishizuka, H. Isago, S. Narikawa, S. Kügler and M. Tamai: Invest. Ophthalmol. Visual Sci. 48 (2007) 3821.

12 K. Kaneda, H. Kasahara, R. Matsui, T. Katoh, H. Mizukami, K. Ozawa, D. Watanabe and T. Isa: PLoS One 6 (2011) e18452.

13 R. Iezzi, P. Finlayson, Y. Xu and R. Katragadda: Conf. Proc. IEEE Eng. Med. Biol. Soc. 2009 (2009) 4563.

14 J. F. Rizzo: J. Neuroophthalmol. 31 (2011) 160.

15 G. J. Chader, J. Weiland and M. S. Humayun: Prog. Brain Res. 175 (2009) 317.

16 F. Gekeler and E. Zrenner: Ophthalmologe 102 (2005) 941.

17 J Ohta, T. Tokuda, K. Kagawa, T. Furumiya, A. Uehara, Y. Terasawa, M. Ozawa, T. Fujikado and Y. Tano: IEEE Eng. Med. Biol. Mag. 25 (2006) 47.

18 S. C. Chen, G. J. Suaning, J. W. Morley and N. H. Lovell: Vision Res. 49 (2009) 1493.

19 S. F. Cogan: Annu. Rev. Biomed. Eng. 10 (2008) 275.

20 S. I. Fried, A. C. Lasker, N. J. Desai, D. K. Eddington and J. F. Rizzo: J. Neurophysiol. 101 (2009) 1972.

21 W. H. Dobelle and M. G. Mladejovsky: J. Physiol. 243 (1974) 553.

22 G. S. Brindley and W. S. Lewin: J. Physiol. 196 (1968) 479.

23 W. H. Dobelle, M. G. Mladejovsky and J. P. Girvin: Science 183 (1974) 440.

24 B. A. Norwood, S. Bauer, S. Wegner, H. M. Hamer, W. H. Oertel, R. S. Sloviter and F. Rosenow: Epilepsia 52 (2011) e109.

25 S. Bojanic, H. Sethi, J. Hyam, J. Yianni, D. Nandi, C. Joint, H. Carter, R. Gregory, P. Bain and T. Z. Aziz: J. Clin. Neurosci. 11 (2004) 732.

26 C. Veraart, C. Raftopoulos, J. T. Mortimer, J. Delbeke, D. Pins, G. Michaux, A. Vanlierde, S. Parrini and M. C. Wanet-Defalque: Brain Res. 813 (1998) 181.

27 I. Obeid, C. Veraart and J. Delbeke: Artif. Organs 34 (2010) 358.

28 J. S. Pezaris and R. C. Reid: IEEE Trans. Biomed. Eng. 56 (2009) 172.

29 J. F. Rizzo, J. Wyatt, M. Humayun, E. de Juan, W. Liu, A. Chow, R. Eckmiller, E. Zrenner, T. Yagi and G. Abrams: Ophthalmology 108 (2001) 13.

30 E. Zrenner, K. D. Miliczek, V. P. Gabel, H. G. Graf, E. Guenther, H. Haemmerle, B. Hoefflinger, K. Kohler, W. Nisch, M. Schubert, A. Stett and S. Weiss: Ophthalmic Res. 29 (1997) 269. 
31 A. Stett, W. Barth, S. Weiss, H. Haemmerle and E. Zrenner: Vision Res. 40 (2000) 1785.

32 C. de Balthasar, S. Patel, A. Roy, R. Freda, S. Greenwald, A. Horsager, M. Mahadevappa, D. Yanai, M. J. McMahon, M. S. Humayun, R. J. Greenwald, J. D. Weiland and I. Fine: Invest. Ophthalmol. Visual Sci. 49 (2008) 2303.

33 R. J. Jensen, J. F. Rizzo, O. R. Ziv, A. Grumet and J. Wyatt: Invest. Ophthalmol. Visual Sci. 44 (2003) 3533.

34 K. Nishida, M. Kamei, M. Kondo, H. Sakaguchi, M. Suzuki, T. Fujikado and Y. Tano: Invest. Ophthalmol. Visual Sci. 51 (2010) 2263.

35 M. S. Humayun, M. Prince, E. de Juan, Y. Barron, M. Moskowitz, I. B. Klock and A. H. Milam: Invest. Ophthalmol. Visual Sci. 40 (1999) 143.

36 J. G. Eng, R. N. Agrawal, K. R. Tozer, F. N. Ross-Cisneros, G. Dagnelie, R. J. Greenwald, G. J. Chader, J. D. Weiland, N. A. Rao, A. A. Sadun and M. S. Humayun: Invest. Ophthalmol. Visual Sci. 28 (2011) 4610.

37 F. Gekeler, P. Szurman, S. Grisanti, U. Weiler, R. Claus, T. O. Greiner, M. Völker, K. Kohler, E. Zrenner and K. U. Bartz-Schmidt: Graefe's Arch. Clin. Exp. Ophthalmol. 245 (2007) 230.

38 T. Fujikado, M. Kamei, H. Sakaguchi, H. Kanda, T. Morimoto, Y. Ikuno, K. Nishida, H. Kishima, T. Maruo, K. Konoma, M. Ozawa and K. Nishida: Invest. Ophthalmol. Visual Sci. 52 (2011) 4726.

39 M. Abramian, N. H. Lovell, J. W. Morley, G. J. Suaning and S. Dokos: J. Neural Eng. 8 (2011) 035004.

40 S. Shah, A. Chu, D. Zhou, R. Greenberg, D. Guven, M. S. Humayun and J. D. Weiland: Conf. Proc. IEEE Eng. Med. Biol. Soc. 6 (2004) 4169.

41 F. Gekeler, K. Kobuch, H. N. Schwahn, A. Stett, K. Shinoda and E. Zrenner: Graefe's Arch. Clin. Exp. Ophthalmol. 242 (2004) 587.

42 E. T. Kim, C. Kim, S. W. Lee, J. M. Seo, H. Chung and S. J. Kim: Invest. Ophthalmol. Visual Sci. 50 (2009) 4337.

43 S. W. Lee, J. M. Seo, S. Ha, E. T. Kim, H. Chung and S. J. Kim: Invest. Ophthalmol. Visual Sci. 50 (2009) 5859.

44 K. I. Koo, S. M. Lee, S. H. Bae, J. M. Seo, H. Chung and D. I. Cho: JMEMS 20 (2011) 251.

45 K. R. Barasch and S. Poler: Am. J. Ophthalmol. 88 (1979) 556.

46 M. F. Refojo: Surv. Ophthalmol. 26 (1982) 257.

47 H. Chung, C. W. Che, S. H. Bae, S. W. Lee, K. I. Koo, J. M. Seo, G. J. Suaning, N. H. Lovell, D. I. Cho and S. J. Kim: ARVO Meeting Abstracts 52 (2011) 2588.

48 E. Guenther, B. Tröger, B. Schlosshauer and E. Zrenner: Vision Res. 39 (1999) 3988.

49 International Standard ISO-10993, Biological Evaluation of Medical Devices Part 1: Evaluation and Testing.

50 E. T. Kim, S. W. Lee, J. M. Seo, H. Chung and S. J. Kim: ARVO Meeting Abstracts 49 (2008) 1773 .

51 J. Stringham, L. Werner, B. Monson, R. Theodosis and N. Mamalis: Ophthalmology 117 (2010) 1486.

52 D. Besch, H. Sachs, P. Szurman, D. Gülicher, R. Wilke, S. Reinert, E. Zrenner, K. U. BartzSchmidt and F. Gekeler: Br. J. Ophthalmol. 10 (2008) 1361.

53 Y. Ninomiya, J. M. Lewis, T. Hasegawa and Y. Tano: Am. J. Ophthalmol. 122 (1996) 613.

54 H. Chung, J. M. Seo, K. A. Kim, H. K. Yu, Y. S. Yu, E. T. Kim, K. I. Koo, D. I. Cho and S. J. Kim: ARVO Meeting Abstracts 47 (2006) 3179.

55 J. Chen, H. A. Shah, C. Herbert, J. I. Loewenstein and J. F. Rizzo: Ophthalmic Res. 42 (2009) 128.

56 A. B. Majji, M. S. Humayun, J. D. Weiland, S. Suzuki, S. A. D’Anna and E. de Juan: Invest. Ophthalmol. Visual Sci. 40 (1999) 2073. 
57 T. Laube, C. Brockmann, G. Roessler, P. Walter, C. Krueger, M. Goertz, S. Klauke and N. Bornfeld: Graefe's Arch. Clin. Exp. Ophthalmol. 250 (2012) 51.

58 S. M. Lee, K. I. Koo, S. M. Ha, J. W. Ban, H. Y. Jeong, H. Park, J. M. Seo, H. Chung and D. I. Cho: ARVO Meeting Abstracts 50 (2009) 4232.

59 H. B. Barlow and R. M. Hill: Science. 139 (1963) 412.

60 H. G. Jansen and S. Sanyal: J. Comp. Neurol. 224 (1984) 71.

61 A. Stett, W. Barth, S. Weiss, H. Haemmerle and E. Zrenner: Vision Res. 40 (2000) 1785.

62 J. H. Ye and Y. S. Goo: Physiol. Meas. 28 (2007) 1079.

63 S. B. Ryu, J. H. Ye, Y. S. Goo, C. H. Kim and K. H. Kim: Invest. Ophthalmol. Visual Sci. 51 (2010) 6762.

64 Y. S. Goo, J. H. Ye, S. Lee, Y. Nam, S. B. Ryu and K. H. Kim: J. Neural Eng. 8 (2011) 035003.

65 D. K. Freeman, D. K. Eddington, J. F. Rizzo and S. I. Fried: J. Neurophysiol. 104 (2010) 2778.

66 R. J. Jensen, O. R. Ziv and J. F. Rizzo: J. Neural Eng. 2 (2005) S16.

67 J. F. Rizzo, J. Wyatt, J. Loewenstein, S. Kelly and D. Shire: Invest. Ophthalmol. Visual Sci. 44 (2003) 5362.

68 A. Y. Chow, V. Y. Chow, K. H. Packo, J. S. Pollack, G. A. Peyman and R. Schuchard: Arch. Ophthalmol. 122 (2004) 460.

69 M. T. Pardue, M. J. Phillips, H. Yin, A. Fernandes, Y. Cheng, A. Y. Chow and S. L. Ball: J. Neural Eng. 2 (2005) S39.

70 J. D. Weiland, A. K. Cho and M. S. Humayun: Ophthalmology 118 (2011) 2227.

71 R. Wilke, V. P. Gabel, H. Sachs, K. U. Bartz-Schmidt, F. Gekeler, D. Besch, P. Szurman, A. Stett, B. Wilhelm, T. Peters, A. Harscher, U. Greppmaier, S. Kibbel, H. Benav, A. Bruckmann, K. Stingl, A. Kusnyerik and E. Zrenner: Invest. Ophthalmol. Visual Sci. 52 (2011) 5995.

72 E. Zrenner, K. U. Bartz-Schmidt, H. Benav, D. Besch, A. Bruckmann, V. P. Gabel, F. Gekeler, U. Greppmaier, A. Harscher, S. Kibbel, J. Koch, A. Kusnyerik, T. Peters, K. Stingl, H. Sachs, A. Stett, P. Szurman, B. Wilhelm and R. Wilke: Proc. Biol. Sci. 278 (2011) 1489.

73 F. Gekeler, K. Kobuch, H. N. Schwahn, A. Stett, K. Shinoda and E. Zrenner. Graefe's Arch. Clin. Exp. Ophthalmol. 242 (2004) 587.

74 H. Chung, J. H. Park, S. J. Kim, E. S. Shin, E. T. Kim, J. M. Jang, S. J. Woo, J. S. Lee, J. M. Seo and S. J. Kim: ARVO Meeting Abstracts 50 (2009) 4221. 